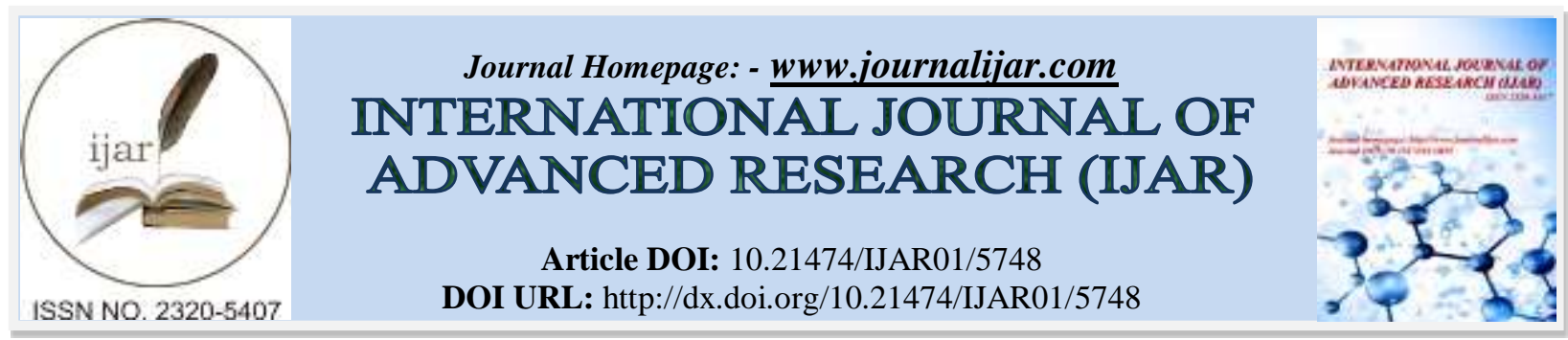

RESEARCH ARTICLE

\title{
POSITIVE EMOTIONS AND RESILIENCE AS PREDICTORS OF FLOURISHING IN WOMEN.
}

Mohsina Nabi ${ }^{1}$ and Touseef Rizvi ${ }^{2}$.

1. Research Scholar Department of Psychology University of Kashmir, Srinagar, J\&K.

2. Sr. Assistant Professor Department of Psychology University of Kashmir, Srinagar, J\&K.

\section{Manuscript Info}

Manuscript History

Received: 02 September 2017

Final Accepted: 04 October 2017

Published: November 2017

Key words:-

Positive Emotions, Resilience,

Flourishing, Women.

\section{Abstract}

Mental health is not only the absence of mental illness, but also the presence of positive wellbeing or flourishing. The higher prevalence rates of mental health problems has put a focus on promoting human flourishing. Women are more susceptible to mental health problems, which may be due to the multiple roles and responsibilities they have taken. Positive mental health, therefore appears to be very essential component of women's health and is a resource to help women to deal with the stresses and challenges of everyday life. The present study draws reference from Fredrickson's Broaden-and-Build theory, which states that various discrete positive emotions (e.g., joy, contentment, interest) broaden one's thought-action repertoire, expanding the range of cognitions and behaviours that come to mind. Over time, these broadened mindsets, in turn, build an individual's physical, intellectual, and social resources, leading an individual towards flourishing. The present study investigated positive emotions and resilience as predictors of flourishing in women. For the same purpose, a sample of 400 women was selected purposively from district Srinagar, with age ranging from 25-60 years $($ Mean $=31.5, \mathrm{SD}=6.5)$. Mental Health Continuum Short Form was used to assess Flourishing, Dispositional Positive Emotions Scale was used to assess positive emotions and EgoResilience Scale was used to assess resilience in women. Results revealed that $39.8 \%$ of women are flourishing, $13.5 \%$ are languishing, while as majority of women i.e., $46.8 \%$ are moderately mentally healthy. Correlational analysis revealed positive and significant correlation between positive emotions and flourishing. Resilience was also positively and significantly correlated with flourishing. Results of regression analysis revealed that positive emotions- awe, contentment, love and pride could predicted $30 \%$ of variance in the model of flourishing in women. However, awe, contentment, love and pride are significant predictors of flourishing. Resilience predicted $16 \%$ of variance in the model of flourishing and thus emerged as a significant predictor.

Copy Right, IJAR, 2017,. All rights reserved.

Mental health is an important factor influencing an individual's behaviour. An individual's mental health is influenced by everyday experiences in all settings. Supportive work, family, and social environments can enhance the capacity of individuals to enjoy life, deal with life's challenges, and achieve wellbeing. Good mental health is 
essentially important to women as it provides a subjective sense of emotional wellbeing to them and it is also a significant resource to the society in which they live and work.

In recent years the role and status of women has changed greatly. Taking on multiple roles, women fulfill household and family responsibilities, and at the same time work outside the home. The complex balance of work, family, and personal fulfillment offers a unique challenge to women today. They are expected to work outside the home as well as to care for the family and be successful in both cases. This builds up a lot of stress in women and can affect their mental health (Panigrahi, Prasad \& Panigrahi, 2014). Women employment has been studied as either beneficial or detrimental to women's psychological well-being. Some studies associate employment of women with better psychological functioning (Elgar \& Chester, 2007), while as other findings have reported poor psychological wellbeing of working women (Suman \& Chatterjee, 2015).

Women experience more mental health problems than men due to the stress of managing many roles (Freeman \& Freeman, 2013). According to WHO report women are more susceptible to depression and anxiety. An estimated 73 million adult women worldwide suffer a major depressive episode each year. The report also says that suicide is the seventh leading cause of death globally for women aged 20-59 years. One in three female suicides worldwide occurs in women between 25 and 44 years of age (WHO, 2009).

\section{Flourishing:-}

While traditional research focused on either hedonic or eudaimonic approaches, definitions of flourishing combine hedonic and eudaimonic elements to create a comprehensive and holistic approach. For example, Keyes (2002) defines flourishing as comprising of three components: (1) emotional (hedonic) wellbeing (2) social wellbeing and (3) psychological (eudaimonic) wellbeing.

According to Keyes (2002) to flourish means to have good mental health, and includes the presence of high levels of emotional, psychological, and social well-being. The term positive mental health is sometimes also used in place of flourishing. The World Health Organization defines mental health as "a state of complete physical, mental and social wellbeing and not merely the absence of disease or infirmity" (WHO, 2010, par. 2). Where flourishing is characterized as the presence of mental health, the absence of mental health is described as languishing (Keyes, 2002). Languishing describes people who feel empty and who have low levels of emotional, psychological, and social well-being (Keyes, 2002). Although languishing has a higher prevalence rate than depression, languishers are not mentally ill. Compared to people who are depressed, adults who are languishing have high emotional distress, challenged relationships, limitations in their daily activities, and miss more work days (Keyes, 2004). Individuals who are neither flourishing nor languishing are diagnosed with moderate mental health.

Huppert and So (2009) examined 23 European countries and found that the highest prevalence of self-reported good health was in flourishers. They also found that flourishing is correlated with higher income and education. Across all countries, those who were married had the highest rates of flourishing while those who were divorced, separated or widowed, had the lowest rate of flourishing. Research also indicates that flourishing individuals are resilient, productive, and experience a high level of positive emotions (Keyes, 2002).

\section{Positive emotions:-}

In the case of positive emotions and health, however, accumulating evidence is providing empirical support for such folk theories. Research shows that positive emotions serve a protecting function and provide a useful remedy to the problems associated with negative emotions and ill health (Fredrickson, 2000). Research has also revealed that while humans are hard-wired to feel negative emotions more strongly, they are also hard-wired to experience positive emotions more frequently.

Like all emotions, positive emotions are brief, multi-system responses to some change in the way people interpret or appraise their current circumstances. The theory which is an exploration of the evolved function of positive emotions is known as the Broaden-and-Build theory developed by Barbara Fredrickson. Fredrickson's (2001) theory is based on two separate but related components referred to as Broaden and Build. The fundamental assumption of the broaden hypothesis is that positive emotions widen attention and focus. Fredrickson proposes that negative emotions (e.g., fear, anger, sadness) are experienced in situations perceived as threatening. Therefore, attention is restricted or narrowed and individuals engage in specific-action tendencies such as escaping, repelling, or attacking. In contrast, positive emotions widen focus and lead to broad, creative, and flexible thinking. 
The second component i.e., the build hypothesis assumes that broadened attention leads to increased engagement with the environment (Fredrickson, 2001). This increased engagement with the environment leads to building of psychological resources, such as self-efficacy and coping skills; cognitive resources, such as reasoning skills and domain-specific knowledge; physical resources, such as effective immune functioning and proper stress regulation; and relational resources, such as intimate relationships and wide social networks.

Consistent with this build hypothesis, ample research has shown that people who experience and express positive emotions more frequently than others are more resilient (Fredrickson, Tugade, Waugh \& Larkin, 2003), resourceful (Lyubomirsky, King, \& Diener, 2005), socially connected (Mauss et al., 2011) and more likely to function at optimal levels (Fredrickson \& Losada, 2005). Positive emotions temporarily broaden people's ways of thinking, which in turn can improve their ways of coping with a current stress. Over time and with repeated experiences of positive emotions, a style of such broad-minded coping might become habitual. And habitual good coping is a durable personal resource, a facet of trait resilience, that functions as a reserve that can be drawn on later to help people bounce back from a wide range of future adversities.

Therefore, positive emotions may help generate resources, maintain a sense of vital energy (i.e., more positive emotions), and create even more resources. Cohn and Fredrickson (2009) referred to this positive sequence as the "upward spiral" of positive emotions. (Figure 1.1).

Figure 1:- A schematic representation of the broaden-and-build theory

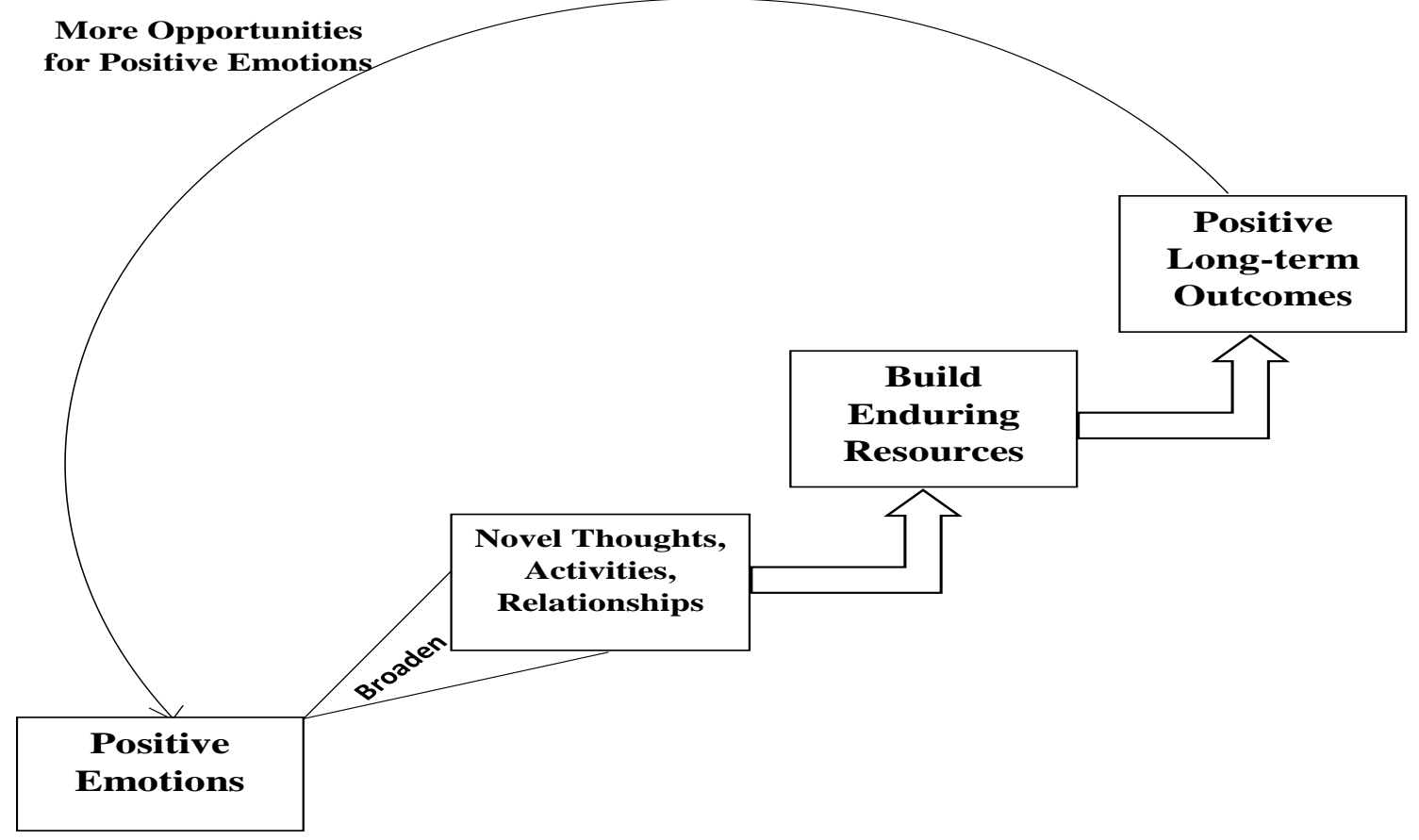

Source: From Cohn, M. A. \& Fredrickson, B. L. (2009). Positive emotions. In S. J. Lopez \& C. R. Snyder (Eds.), Oxford handbook of positive psychology (pp. 13-24).

\section{Resilience:-}

Resilience, or the ability to overcome challenges, is often mentioned as a favorable human trait. Indeed, one aspect of positive human functioning is when a person faces significant life challenges and has to overcome adversity (Ryff \& Singer, 2003). Stress and adversity can come in the shape of family or relationship problems, health problems, or workplace and financial worries, among others (American Psychological association [APA], 2014).

Trait-resilient individuals experience positive emotions even in the midst of stressful events, which may explain their ability to rebound successfully despite adversity. This suggests that trait-resilient people may understand the 
benefits associated with positive emotions and use this knowledge to their advantage when coping with negative emotional events (Tugade \& Fredrickson, 2004). Positive emotions may help build ego-resilience, yet ego-resilience also functions partly by generating positive emotions. When faced with a stressor, people high on ego resilience experience more positive emotions than their less resilient peers, even though they experience negative emotions at comparable levels. The difference in positive emotions accounts for their better ability to rebound from adversity and stress, ward off depression, and continue to grow (Fredrickson, et. al, 2003; Ong, Bergeman, Bisconti \& Wallace, 2006; Tugade \& Fredrickson, 2004).

\section{Purpose of the study:-}

Interest in how to enhance human wellbeing is growing and pleasant emotional states appear to be critical constituents of human flourishing. Psychological research has established that high levels of positive emotion promote well-being (Seligman \& Csikszentmihalyi, 2000). The present study draws reference from the broaden-andbuild theory, which states that various discrete positive emotions (e.g., joy, contentment, interest) broaden one's thought-action repertoire, expanding the range of cognitions and behaviours that come to mind. These broadened mindsets, in turn, build an individual's physical, intellectual, and social resources. The present study aims to test the build hypothesis of the broaden-and-build theory.

The objective of the present study was to ascertain the role of positive emotions and resilience as predictors of flourishing. Because flourishing individuals are characterized as being free of depression as well as having the presence of positive emotion and positive functioning. Using Keyes' categorical diagnosis, the present study also estimates the prevalence of positive mental health (i.e., flourishing) in the population of women between the age of 25 and 60 years.

\section{Objectives of the Study:-}

The main objectives of the study are as follows:

1. To assess positive emotions, resilience and flourishing in women.

2. To study the correlation between positive emotions, resilience and flourishing in women.

3. To study positive emotions and resilience as predictors of flourishing in women.

\section{Participants:-}

A total of 400 women were selected purposively from district Srinagar, with age ranging from 25-60 years (Mean $=$ $31.5, \mathrm{SD}=6.5$ ). Of the total participants, 200 were working and 200 were non-working. The sample was chosen with the following inclusion criteria:

a) Women who were willing to participate in the study.

b) Women who were literate.

c) Women who were in the age range of 25 years to 60 years.

Table 1: Description of the sample

\begin{tabular}{|c|c|c|c|}
\hline Demographic variables & Groups & Frequency & Percentage\% \\
\hline \multirow{3}{*}{ Age } & $25-36$ & 319 & 79.75 \\
\cline { 2 - 4 } & $37-46$ & 65 & 16.25 \\
\cline { 2 - 4 } & $47-60$ & 16 & 4 \\
\hline \multirow{2}{*}{ Occupational status } & Working & 200 & 50 \\
\cline { 2 - 4 } & Non-working & 200 & 50 \\
\hline \multirow{3}{*}{ Profession } & Teachers & 67 & 33.5 \\
\cline { 2 - 4 } & Doctors & 68 & 32.5 \\
\cline { 2 - 4 } & Lawyers & 65 & 50.4 \\
\hline \multirow{2}{*}{ Marital status } & Married & 202 & 49.4 \\
\cline { 2 - 4 } & Unmarried & 198 & 38.7 \\
\hline Family type & Joint & 245 & 61.1 \\
\cline { 2 - 4 } & Nuclear & 97 & 24.2 \\
\hline Educational level & Graduation & 303 & 75.6 \\
\cline { 2 - 4 } & Higher & & \\
\hline
\end{tabular}

\section{Research Instruments:-}

Following research instruments were used for the present study. 
Mental Health Continuum Short Form (MHC-SF) (Keyes, 2002) was used to assess Flourishing. It consists of 14 items measuring Emotional Well-being (3 items), Psychological Well-being (5 items) and Social Well-being (6 items). The alpha coefficient in the present study for overall Flourishing scale was .72 and the alpha coefficients for the subscales were as follows: emotional wellbeing, .82; social wellbeing, .61; and psychological wellbeing, 76 .

Categorical Diagnosis: A diagnosis of flourishing is made if someone feels 1 of the 3 emotional well-being symptoms (items 1-3) "every day" or "almost every day" and feels 6 of the 11 positive functioning symptoms (items 4-8 are indicators of social well-being and 9-14 are indicators of psychological well-being) "every day" or "almost every day" in the past month. Languishing is the diagnosis when someone feels 1 of the 3 emotional wellbeing symptoms (items 1-3) "never" or "once or twice" and feels 6 of the 11 positive functioning symptoms (items 4-14) "never" or "once or twice" in the past month. Individuals who are neither languishing nor flourishing are then coded as moderately mentally healthy (see Appendix D).

Dispositional Positive Emotions Scale (DPES) (Shiota, Dacher \& John, 2006) was used to assess positive emotions. It is a 38-item self-report instrument with seven subscales (Joy, Contentment, Amusement, Pride, Awe, Love and Compassion), each subscale consists of 5 or 6 items. Participants report their agreement on a 7 - point scale ranging from (1) strongly agree to (7) strongly disagree. In the present study the alpha coefficient for DPES was found to be .86 which is very good. Cronbach's alpha for the subscales was as follows: Amusement, .65; Awe, .68; Compassion, .71; Contentment, .85; Joy, .66; Love, .70 and Pride, .74.

The Ego-Resilience Scale (Block \& Kremen, 1996) was used to assess psychological resilience, defined as "the capacity of the individual to effectively modulate and monitor an ever changing complex of desires and reality constraints" (Block \& Kremen). The scale consists of 14 items, each responded to on a 4-point Likert scale, ranging from (1) does not apply at all to (4) apply very strongly. Cronbach's alpha in the present sample for the scale was also found to be $\operatorname{good}(\alpha=.70)$.

Demographic Variables Questionnaire was constructed to obtain information regarding age, marital status, occupation, educational qualification, and type of family.

\section{Procedure:-}

The researcher approached the Principals, Medical Superintendents and heads of various institutions (viz, schools, hospitals) in order to obtain permission for the collection of data. After obtaining the approval of the authorities, each participant was informed about the purpose of the study and verbal consent for participation in the study was taken. The researcher also emphasized the confidentiality of their responses provided in the questionnaire.

\section{Results:-}

Table 2: Frequency distribution of women on different levels of positive emotions and resilience

\begin{tabular}{|c|c|c|c|c|c|c|}
\hline \multirow{2}{*}{ Variables } & \multicolumn{2}{|c|}{ Low } & \multicolumn{2}{c|}{ Levels Average } & \multicolumn{2}{c|}{ High } \\
\cline { 2 - 6 } & $\boldsymbol{f}$ & $\mathbf{\%}$ & $\boldsymbol{f}$ & $\mathbf{\%}$ & $\boldsymbol{f}$ & $\mathbf{\%}$ \\
\hline Amusement & 69 & 17.25 & 265 & 66.25 & 66 & 16.5 \\
\hline Awe & 71 & 17.75 & 261 & 65.25 & 68 & 17 \\
\hline Compassion & 53 & 13.25 & 269 & 67.25 & 78 & 19.5 \\
\hline Contentment & 63 & 15.75 & 292 & 73 & 45 & 11.25 \\
\hline Joy & 67 & 16.75 & 264 & 66 & 69 & 17.25 \\
\hline Love & 73 & 18.25 & 266 & 66.5 & 61 & 15.25 \\
\hline Pride & 54 & 13.5 & 305 & 76.25 & 41 & 10.25 \\
\hline Total positive emotions & 41 & 10.25 & 296 & 74 & 63 & 15.75 \\
\hline Resilience & 62 & 15.5 & 269 & 67.25 & 69 & 17.25 \\
\hline
\end{tabular}

Table 3:- Categorical diagnosis of women on flourishing

\begin{tabular}{|l|c|c|}
\hline Categories & Frequency & \% \\
\hline Flourishing & 159 & 39.8 \\
\hline Moderately mentally healthy & 187 & 46.8 \\
\hline Languishing & 54 & 13.5 \\
\hline
\end{tabular}


It is evident from table 4.4 that $39.8 \%$ of women are flourishing (i.e. having high social, emotional and psychological wellbeing), $13.5 \%$ are languishing (i.e. having low social, emotional and psychological wellbeing), while as majority of women i.e., $46.8 \%$ are moderately mentally healthy (neither flourishing nor languishing).

Table 4: Summary of Pearson Correlations between positive emotions and flourishing

\begin{tabular}{|c|c|c|c|c|}
\hline \multirow{2}{*}{$\begin{array}{c}\text { Positive emotions } \\
\downarrow\end{array}$} & \multicolumn{3}{|c|}{ Dimensions of Flourishing } & \multirow[t]{2}{*}{ Total Flourishing } \\
\hline & Emotional wellbeing & $\begin{array}{c}\text { Social } \\
\text { wellbeing }\end{array}$ & $\begin{array}{l}\text { Psychological } \\
\text { wellbeing }\end{array}$ & \\
\hline Amusement & $.12 *$ & 0.08 & -0.06 & 0.05 \\
\hline Awe & $.32 * *$ & $.31 * *$ & $.25 * *$ & $.39 * *$ \\
\hline Compassion & -0.2 & 0.05 & $.19 * *$ & $.17 *$ \\
\hline Contentment & $.53 * *$ & $.14 * *$ & $.13 * *$ & $.33 * *$ \\
\hline Joy & $.36 * *$ & $.25 * *$ & 0.07 & $.28 * *$ \\
\hline Love & $.19 * *$ & $.28 * *$ & $.18 * *$ & $.30 * *$ \\
\hline Pride & $.17 * *$ & $.24 * *$ & $.46 * *$ & $.42 * *$ \\
\hline Total Positive emotions & $.43 * *$ & $.33 * *$ & $.28 * *$ & $.46^{* *}$ \\
\hline$* P \leq 0.05 ; * * P \leq 0.01$ & & & & \\
\hline
\end{tabular}

Almost all positive emotions were found to be significantly correlated with all three dimensions of flourishing i.e., emotional wellbeing, social wellbeing and psychological wellbeing as well as with overall score. The results revealed that Awe, Compassion Contentment, Joy, Love and Pride are significantly and positively correlated with total flourishing. However, Amusement showed correlation only with emotional wellbeing dimension of flourishing. Compassion did not show significant correlation with emotional and social wellbeing dimensions of flourishing. Also Joy did not show significant correlation with psychological wellbeing dimension of flourishing.

Table 5:- Summary of Pearson Correlations between resilience and flourishing

\begin{tabular}{|c|c|c|c|c|}
\hline \multicolumn{4}{|c|}{ Dimensions of Flourishing } & \multicolumn{2}{c|}{ Total Flourishing } \\
\hline & $\begin{array}{c}\text { Emotional } \\
\text { wellbeing }\end{array}$ & Social wellbeing & $\begin{array}{c}\text { Psychological } \\
\text { wellbeing }\end{array}$ & \\
\hline Resilience & $.20^{* *}$ & $.22^{* *}$ & $.45^{* *}$ & $.40^{* *}$ \\
\hline
\end{tabular}

$* * P \leq 0.01$

The above table shows that resilience is positively and significantly correlated with flourishing.

For predicting flourishing in women, regression analysis was used. Multiple analysis was applied to find the significant predictors and to investigate the degree to which flourishing could be explained by positive emotions and resilience.

Table 6: Multiple regression analysis (ANOVA Summary)

\begin{tabular}{|l|c|c|c|c|}
\hline & Sum of squares & df & Mean square & F \\
\hline Regression & 15160.92 & 6 & 2526.82 & 28.23 \\
\hline Residual & 35169.05 & 393 & 89.48 & \\
\hline Total & 50329.97 & 399 & & \\
\hline
\end{tabular}

a. Predictors: (constant); awe, compassion, contentment, joy, love, pride

b. Dependent variable: Flourishing

Table 7: Multiple regression analysis (Summary of Predictor variables)

\begin{tabular}{|l|c|c|c|c|}
\hline \multicolumn{1}{|c|}{ Model } & \multicolumn{2}{c|}{$\begin{array}{c}\text { Unstandardized } \\
\text { coefficients }\end{array}$} & $\begin{array}{c}\text { Standardized } \\
\text { coefficients }\end{array}$ & t \\
\hline & B & Std. Error & Beta & \\
\hline (Constant) & 8.42 & 4.67 & - & $1.80(\mathrm{p}=.07)$ \\
\hline Awe & 2.08 & .56 & .18 & $3.7(\mathrm{p}=.001)$ \\
\hline Compassion & -1.57 & .73 & -0.9 & $2.12(\mathrm{p}=.03)$ \\
\hline Contentment & 1.67 & .43 & .19 & $3.87(\mathrm{p}=.001)$ \\
\hline
\end{tabular}




\begin{tabular}{|l|c|c|c|c|}
\hline Joy & -1.76 & .64 & -0.1 & $.27(\mathrm{p}=.78)$ \\
\hline Love & 1.52 & .44 & .16 & $3.46(\mathrm{p}=.001)$ \\
\hline Pride & 3.50 & .55 & .30 & $6.27(\mathrm{p}=.001)$ \\
\hline
\end{tabular}

Dependent variable: Flourishing

Table shows that $30 \%$ of variance in flourishing can be attributed to Awe, Compassion, Contentment, Joy, Love and Pride. However, Awe, Contentment, Love and Pride are significant predictors of flourishing, as their beta values are significant.

Table 8: Regression analysis (ANOVA Summary)

\begin{tabular}{|l|c|c|c|c|}
\hline & Sum of squares & Df & Mean square & F \\
\hline Regression & 8423.984 & 1 & 8423.984 & 80.006 \\
\hline Residual & 41905.994 & 398 & 105.291 & \\
\hline Total & 50329.978 & 399 & & \\
\hline
\end{tabular}

a. Predictors: (constant), resilience

b. Dependent variable: Flourishing

Table 9: Regression analysis (Summary of Predictor variables)

\begin{tabular}{|l|c|c|c|c|}
\hline \multicolumn{1}{|c|}{ Model } & \multicolumn{2}{|c|}{ Unstandardized coefficients } & $\begin{array}{c}\text { Standardized } \\
\text { coefficients }\end{array}$ & t \\
\hline & B & Std. Error & Beta & \\
\hline (Constant) & 10.96 & 3.38 & - & $3.24(\mathrm{p}=.001)$ \\
\hline Resilience & .73 & .08 & .40 & $8.94(\mathrm{p}=.001)$ \\
\hline
\end{tabular}

Dependent variable: Flourishing

The above table shows that resilience predicts $16 \%$ of variance in the model of flourishing and thus emerges as a significant predictor of flourishing.

\section{Discussion:-}

Findings of the present study revealed that positive emotions and resilience are significantly related to flourishing and they significantly predict flourishing. The finding is in line with the Broaden and Build theory of positive emotions, particularly validating the build hypothesis of the theory. It also supports previous literature. Lyubomirsky, King, and Diener (2005) conducted a meta-analysis of 293 cross-sectional, longitudinal, and experimental studies (resulting in a sample of over 275,000 participants) and found that positive emotions had a causal influence on social outcomes, work outcomes, physical health outcomes, personal outcomes and psychological outcomes.

Van Zyl \& Rothmann (2012) examined the relationship between flourishing and academic performance, life satisfaction, and positive affect found that flourishing students experienced higher levels of positive affect and life satisfaction, as well as lower levels of negative affect than languishing and moderately flourishing students. Nath and Kumar (2012) examining the influence of positive affect on physical health and psychological well-being (PWB) on a sample of students $(\mathrm{N}=146)$, found significant relationship between positive affect and PWB and also resilience significantly mediated between positive affect and PWB (a component of flourishing). Some studies have examined the relationship between resilience, positive emotions and psychological wellbeing (which is one of the dimensions of flourishing). Pidgeon \& Keye (2014) studied the relationship between resilience, mindfulness and PWB revealed that mindfulness and resilience predicted $51 \%$ of the variance of PWB scores, with resilience accounting for the greatest amount $(47 \%)$ of variance.

Our results also found that more teachers were flourishing and less of them were languishing as compared to doctors and lawyers. This finding is consistent with the previous literature. Srimathi and Kumar (2010) in their research study examined the level of psychological wellbeing among working women in different organizations - industries, hospitals, banks, educational institutions and in call centers/BPOs and found that women teachers had highest psychological wellbeing. The present finding is also supported by Rastogi and Kashyap (2001) who reported that teachers had better mental health than compared to other professionals. 


\section{Practical Implications of the Study:-}

The findings of present study are made more significant as research suggests that high wellbeing has preventative effects on the development of mental health problems over time (Suldo \& Huebner, 2004). As positive affect positive emotions, positive moods and positive attitudes may be the single most important active ingredient in the recipe for human flourishing (Fredrickson \& Branigan, 2005) and the present study supports the same, therefore, the focus should be on cultivating positive emotions for promoting flourishing in women. Because, women experience more mental health problems than men due to the stress of managing many roles (Freeman \& Freeman, 2013) and WHO report also highlights that women are more susceptible to depression and anxiety. (WHO, 2009). Therefore, the focus of mental health professionals should be to cultivate meaningful positive emotions in women. This work should be made easy by the finding that a number of studies, utilizing various emotion elicitation paradigms, have indicated that women report more frequent or more intense emotion for both positive and negative emotions (Tobin, Graziano, Vrana and Rollock, 2002).

A wide range of positive psychology interventions (PPIs) have now been developed and tested, from brief, self-help interventions of short duration to more in-depth intervention programs, involving group work or one-to-one therapeutic input. Following are some of the PPIs that have been found to increase positive emotions and are readily researched:

1. Gratitude exercise.

2. Savoring.

3. Loving-kindness meditation

4. Expressive writing interventions

\section{References:-}

1. American Psychological Association. (2014). The Road to Resilience. Washington, DC. Retrieved from http://www.apa.org/helpcenter/road-resilience.aspx.

2. Block, J., \& Kremen, A. M. (1996). IQ and ego-resiliency: Conceptual and empirical connections and separateness. Journal of Personality and Social Psychology, 70, 349-361.

3. Cohn, M. A. \& Fredrickson, B. L. (2009). Positive emotions. In S. J. Lopez \& C. R. Snyder (Eds.), Oxford handbook of positive psychology (pp. 13-24). New York: Oxford University Press.

4. Elgar, K., \& Chester, A. (2007). The mental health implication of maternal employment. Australian Journal for the Advancement of Mental Health, 6, 1-9.

5. Fredrickson, B. L. \& Losada, F. (2005). Positive affect and the complex dynamics of human flourishing. American Psychologist, 60, 678-686.

6. Fredrickson, B. L. (2000). Cultivating positive emotions to optimize health and well-being. Prevention and treatment, 3, 1-25. Retrieved from http://journals. apa.org/prevention.

7. Fredrickson, B. L. (2001). The role of positive emotions in positive psychology: The broaden-and-build theory of positive emotions. American Psychologist, 56, 218-226.

8. Fredrickson, B. L., \& Branigan, C. (2005). Positive emotions broaden the scope of attention and thought-action repertoires. Cognition and Emotion, 19, 313-332.

9. Fredrickson, B. L., Tugade, M. M., Waugh, C. E., \& Larkin, G. R. (2003). What good are positive emotions in crises? A prospective study of resilience and emotions following the terrorists attacks on the United States on September 11, 2001. Journal of Personality and Social Psychology, 84, 365-376.

10. Fredrickson, B. L., Tugade, M. M., Waugh, C. E., \& Larkin, G. R. (2003). What good are positive emotions in crises? A prospective study of resilience and emotions following the terrorists attacks on the United States on September 11, 2001. Journal of Personality and Social Psychology, 84, 365-376.

11. Freeman, D. \& Freeman, J. (2013). The Stressed Sex: Uncovering the Truth about Men, Women, and Mental Health. Oxford: Oxford University Press.

12. Huppert, F. A., \& So, T. C. (2009). What percentage of people in Europe are flourishing and what characterises them? Measuring Subjective well-being: An Opportunity for NGOs? OECD/ISQOLS meeting, Florence, Italy, 23-24 July.

13. Keyes, C. L. M. (2002). The mental health continuum: From languishing to flourishing in life. Journal of Health and Social Behavior, 43, 207-222.

14. Keyes, C. L. M. (2004). The nexus of cardiovascular disease and depression revisited: The complete mental health perspective and the moderating role of age and gender. Aging and Mental Health, 8, 266-274.

15. Lyubomirsky, S., King, L., \& Diener, E. (2005). The benefits of frequent positive affect: Does happiness lead to success? Psychological Bulletin, 131, 803-835. 
16. Mauss, I. B., Savino, N. S., Anderson, C. L., Weisbuch, M., Tamir, M., \& Laudenslager, M. L. (2011). The pursuit of happiness can be lonely. Manuscript submitted for publication.

17. Nath, P. \& Pradhan, R. K. (2012). Influence of positive affect on physical health and psychological wellbeing: Examining the mediating role of resilience. Journal of Health Management, 14(2), 161-174. doi: $10.1177 / 097206341201400206$

18. Ong, A. D., Bergeman, C. S., Bisconti, T. L., \& Wallace, K. A. (2006). Psychological resilience, positive emotions, and successful adaptation to stress in later life. Journal of Personality and Social Psychology, 91, 730-749.

19. Panigrahi, A., Prasad, A., \& Panigrahi, M. (2014). Mental health status among married working women residing in Bhubaneswar city India: A psychosocial survey. BioMed Research International. doi: 10.1155/2014/979827

20. Pidgeon, A. M., \& Keye, M. (2014). Relationship between resilience, mindfulness, and psychological wellbeing in university students. International Journal of Liberal Arts and Social Science, 2(5), 27-32.

21. Rastogi, R. \& Kashyap, K., (2001). A study of occupational stress and mental health among married working women. J. Com. Guid. Res., 18(2), 189-196.

22. Ryff, C. D., \& Singer, B. (2003). Thriving in the face of challenge: The integrative science of human resilience. In F. Kessel, P. L. Rosenfield, \& N. B. Anderson (Eds.), Expanding the boundaries of health and social science: Case studies in interdisciplinary innovation, (pp.181-205). New York: Oxford University Press.

23. Seligman, M. E. P., \& Csikszentmihalyi, M. (2000). Positive psychology: An introduction. American Psychologist, 55, 5-14.

24. Shiota, M. N., Keltner, D., \& John O. P. (2006). Positive emotion dispositions differentially associated with Big Five personality and attachment style. Journal of Positive Psychology, 1, 61-71.

25. Srimathi, N. L., \& Kiran Kumar, S. K. (2010). Psychological wellbeing of employed women across different organisations. Journal of the Indian Academy of Applied Psychology, 36(1), 89-95.

26. Suldo, S. M. \& Huebner, E. S. (2004). Does life satisfaction moderate the effects of stressful events on psychopathological behavior during adolescence? School Psychology Quarterly, 19, 93-105.

27. Suman, V. B., \& Chatterjee, P. (2015). Psychological and physical well-being in working women. Int J Med Sci Public Health, 4(11), 1489-1492. doi: 10.5455/ijmsph.2015.11022015307

28. Tobin, R., M., Graziano, W., G., Vanman, E., J., \& Tassinary, L., G. (2000). Personality, emotional experience and efforts to control emotions. Journal of Personality and Social Psychology, 79(4), 656.

29. Tugade, M. M., \& Fredrickson, B. L. (2004). Resilient individuals use positive emotions to bounce back from negative emotional experiences. Journal of Personality and Social Psychology, 86, 320-333.

30. Tugade, M. M., Fredrickson, B. L., \& Barrett, L. F., (2004). Psychological resilience and positive emotional granularity: Examining the Benefits of positive emotions on coping and health. Journal of Personality 72, 6.

31. Van Zyl, L., E., \& Rothmann, S. (2012). Flourishing of students in a tertiary education institution in South Africa. Journal of Psychology in Africa, 22(4), 593-604.

32. WHO (2009). Women and Health: Today's evidence tomorrow's agenda. Geneva: World Health Organisation.

33. World Health Organization. (2010, September 10). Mental health: Strengthening our response. [Fact sheet] Retrieved from: http://www.who.int/mediacentre /factsheets /fs220/en/ 